\title{
AC 2012-3000: DESIGN, SIMULATION, AND FABRICATION OF AN IN- TELLIGENT GROUND VEHICLE AS A PART OF THE CAPSTONE PROJECT
}

\author{
Mr. Nicholas Charles Cappello, York College of Pennsylvania
}

Nicholas Charles Cappello received his B.Sc. degree in mechanical engineering in Aug. 2011 from York College of Pennsylvania and is pursuing a master's degree in mechanical engineering at Oregon State University with the expectation to become involved in research. He is especially interested in thermodynamics and fluids because of their application in renewable energies but also holds interest in biomechanical systems because of their high efficiency and adaptability.

\section{Mr. Takeshi Jonathan Ei, York College of Pennsylvania}

Following six years of Naval service, Takeshi Jonathan Ei commenced undergraduate studies at Northampton Community College in Bethlehem, Penn. He then transferred to York College of Pennsylvania and graduated with a bachelor's of science in mechanical engineering in June 2011. Ei has interests in marine systems and power generation technologies and plans to pursue a postgraduate degree and a career in the field of commercial or military shipbuilding.

\section{Mr. Edward Miller Jr., York College of Pennsylvania}

Edward Miller received his B.Sc. degree in electrical engineering in Aug. 2011 from York College of Pennsylvania. Miller is interested in power systems and renewable energy technologies. He plans to pursue a postgraduate degree, as well as becoming a certified Professional Engineer while working for an electrical engineering consulting firm in Pennsylvania.

\section{Dan Bosse, Weldon Solutions}

Dan Bosse graduated from York College of Pennsylvania with a degree in mechanical engineering in the summer of 2011. He now works at Weldon Solutions in York, Penn., designing automation systems and precision grinders. The capstone design project was one of the highlights of his time at York College. Given the opportunity, he would gladly work on another robotics project.

\section{Berne S. Edwards, Graham Packaging Company}

Berne Edwards received his B.Sc. degree in mechanical engineering from York College of Pennsylvania in 2011 and works as a Project Management Engineer at Graham Packaging Company under the Global Technology Group. Also, Edwards plans to complete a postgraduate degree in business administration, which will help further develop his managerial skills. Edwards's interests include electro-mechanical and control systems because it allows him to know how systems work and what drives each of their functions.

\section{Dr. Kala Meah, York College of Pennsylvania}

Kala Meah received a B.Sc. degree from Bangladesh University of Engineering and Technology in 1998, a M.Sc. degree from South Dakota State University in 2003, and a Ph.D. degree from the University of Wyoming in 2007, all in electrical engineering. From 1998 to 2000, he worked for several power companies in Bangladesh. Currently, Meah is an Assistant Professor in the electrical and computer engineering program, Department of Physical Sciences, York College of Pennsylvania, York, Penn., USA. His research interest includes electrical power, HVDC transmission, renewable energy, energy conversion, and engineering education.

\section{Dr. Stephen N. Kuchnicki, York College of Pennsylvania}

Stephen N. Kuchnicki is an Assistant Professor of mechanical engineering at York College of Pennsylvania. Previously, he was a Postdoctoral Research Associate at Rutgers University, specializing in computational modeling of dynamic deformations in solids. His areas of technical expertise include solid mechanics, crystal plasticity, vibration, and fluid-structure interaction. He received his Ph.D. from Rutgers University in 2001. 


\section{Dr. Gregory M. Link, York College of Pennsylvania}

Gregory Link received his Ph.D. from the Pennsylvania State University in 2006 for work relating to temperature-aware architectures. Since then, he has worked as an Assistant Professor of electrical and computer engineering at the York College of Pennsylvania, where his interests include embedded systems design, reliable firmware development, and engineering education.

\section{Dr. Wayne Blanding, York College of Pennsylvania}

Wayne Blanding received his B.S. degree in systems engineering from the U.S. Naval Academy, ocean engineer degree from the MIT/Woods Hole Joint program in ocean engineering, and Ph.D. in electrical engineering from the University of Connecticut. From 1982 to 2002, he was an officer in the U.S. Navy's submarine force. He is currently an Assistant Professor of electrical engineering at York College of Pennsylvania. He is a Senior Member of the IEEE. He was Publications Chair for the 2009 and 2011 International Conferences on Information Fusion, and is in the Publications Committee for the IEEE Aerospace Conference (2008-present). His research interests include target tracking, detection and estimation.

\section{Dr. Scott F. Kiefer, York College of Pennsylvania}

Scott Kiefer has spent the past 11 years teaching mechanical engineering at four institutions. As an exemplary teaching specialist in mechanical engineering at Michigan State University, Kiefer received the Withrow Award for Teaching Excellence, given to one faculty member in the College in Engineering for outstanding instructional performance. Kiefer specializes in machine design, vibrations and controls, and mechatronics. He started his career at the University of Puerto Rico, Mayagez, in the traditional role of teaching and administering a modest research program. At Trine University, a small private school in Angola, Ind., Kiefer taught 10 different courses from introductory freshman courses to senior design, while serving as advisor to many undergraduate research projects. He recently moved to York College of Pennsylvania where he will be able to concentrate on undergraduate education in mechanical engineering. 


\title{
Design, Simulation, and Fabrication of an Intelligent Ground Vehicle as a Part of the Capstone Project
}

\begin{abstract}
A team of undergraduate engineering students from York College of Pennsylvania (YCP) constructed an autonomous ground vehicle for the capstone design courses required by their engineering curricula. The team's vehicle was entered in the $19^{\text {th }}$ annual Intelligent Ground Vehicle Competition (IGVC) at Oakland University in Rochester, Michigan, where it achieved a top ten overall standing among 55 contestants and earned an award for vehicle design. This paper provides an overview of the capstone design experience of the project's structure and motion sub-team, which was responsible for the design and implementation of the vehicle's mechanical, electromechanical, and electrical distribution systems. In particular, design, simulation, and fabrication of the vehicle are presented. This paper also discusses the organization, planning and resource acquisition challenges faced by this interdisciplinary team. The chosen design is modeled in Simulink ${ }^{\mathrm{TM}}$ software; the results are validated by comparing the simulated response to competition and pre-event testing of the as-fabricated vehicle. Project outcomes are presented and assessed with respect to YCP's capstone design expectations and program outcomes, as well as compliance with technical specifications established within the IGVC rules and by the team.
\end{abstract}

\section{Introduction}

The engineering programs at York College of Pennsylvania (YCP) [1] emphasize the engineering design process through participation in numerous team-oriented projects. These projects expose students to a battery of challenges that stimulate innovation, as well as strengthen the knowledge and skill sets acquired from academic coursework. Projects early in the curriculum typically involve an internal client (such as faculty). Those later in the curriculum introduce external competition-based projects. The projects bring real world considerations into the mix, such as design constraints, scheduling, logistics, financing and various other project management concerns.

The design curriculum culminates in a two-semester capstone design project that encompasses the full scope of engineering design and standard program outcomes [2]. The capstone design projects are intended to be a design/build/test project for an external audience. Students are assessed for the technical work and independent learning necessary in the design phase, the ability to assemble the overall prototype, and the quality of testing and validation work performed on the prototype.

One of the current projects at YCP reflect the growing need for multidisciplinary thinking [2] and the application of a broad range of engineering tools: the Intelligent Ground Vehicle Competition (IGVC) project. For the 2010-11 academic year, a team of ten computer, electrical and mechanical engineering students designed and fabricated an all-new ground vehicle for YCP's second showing at the IGVC [4]. The vehicle was designed for autonomous operation to include the capabilities of detecting and reacting to obstacles in its path, recognizing and following established lanes, and navigating to and from prescribed way points. A variety of sensing, computing, structural, and electromechanical technologies were utilized, underscoring the multidisciplinary project format. Figure 1a shows the final form of Sparta, the IGVC capstone design project for the 2010-11 academic year at YCP, which was first visualized through the computer aided design seen in Figure $1 \mathrm{~b}$. The remainder of this paper will detail the design of the structural and motion systems of this autonomous vehicle. 


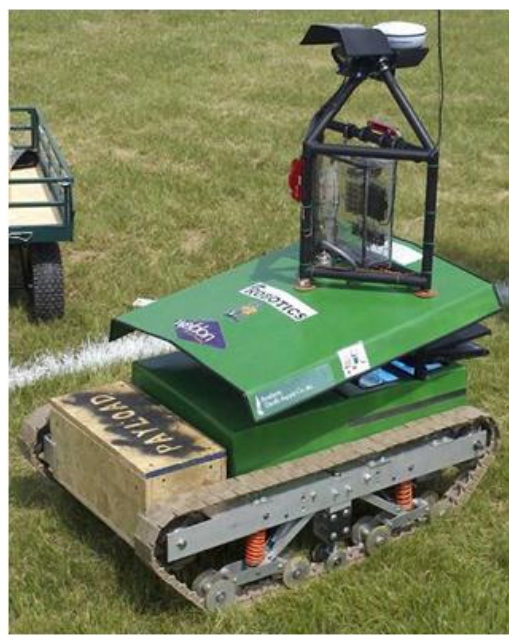

(a)

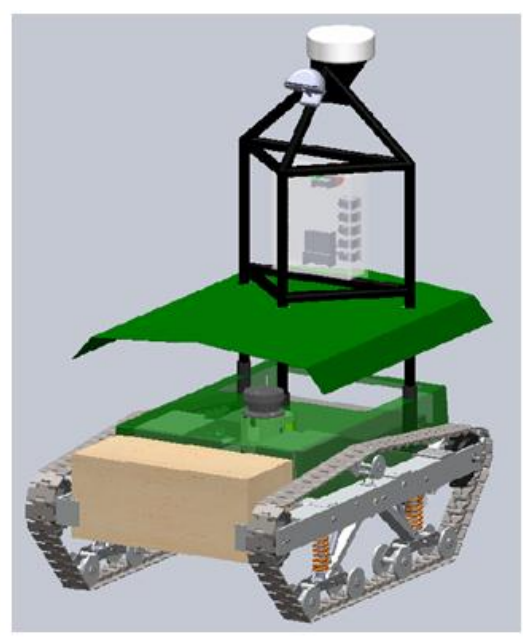

(b)

Figure 1: Sparta shown in final form (a) and as drawn using computer-aided design (b)

\section{Capstone Design Course Structure}

The engineering curricula at YCP are among a relative few in the United States that require a full year of cooperative work experience (co-op) as a required part of the curriculum. In order to accommodate this feature of the programs without adding a fifth year to the engineering curricula, the engineering programs operate on a full year cycle. The summer term is a standard academic term, encompassing 13 weeks from May to August. Students take courses in the summer of the junior and senior years while working as a co-op in the spring of the junior year and the fall of the senior year.

For these reasons, Capstone Design at YCP is a two-part course that begins in the summer semester of the students' junior academic year. The summer can be considered the "design" portion of the course. Students develop project specifications, establish their project budgets and timelines, and iterate on possible designs to meet their requirements. Analysis is performed on many different designs, and students are expected to complete the summer with a comprehensive design in hand and a Gantt Chart detailing how the build phase of the project will take place. These aspects are assessed via a formal design review presentation for engineering faculty and representatives of local industry.

The second part of the course, administered in the spring semester of the senior year, serves as the execution phase. This encompasses the build and test portions of the capstone design projects, in which the team completes all steps necessary to construct the project and validate compliance with all applicable specifications. Redesign and remanufacture are often necessary in this stage of the project, depending upon the results of the tests performed.

The design process is a student led initiative intended to instill a capacity for life-long learning, develop leadership skills, and promote professional conduct. Faculty advisors assigned to projects play a role similar to upper management where involvement is limited to high level functions such as authorizing major expenditures, collecting periodic status reports, and directing the team as required. Faculty also set high-level deadlines, such as the requirement to have a completed design in hand at the end of the summer term, and create the organizational structure of the student teams. Other engineering faculty members who are not teaching the course may be consulted as subject matter experts within their 
respective fields. However, students are encouraged to seek resolution on issues through independent research whenever possible. Figure 2 shows the design process and major milestones.

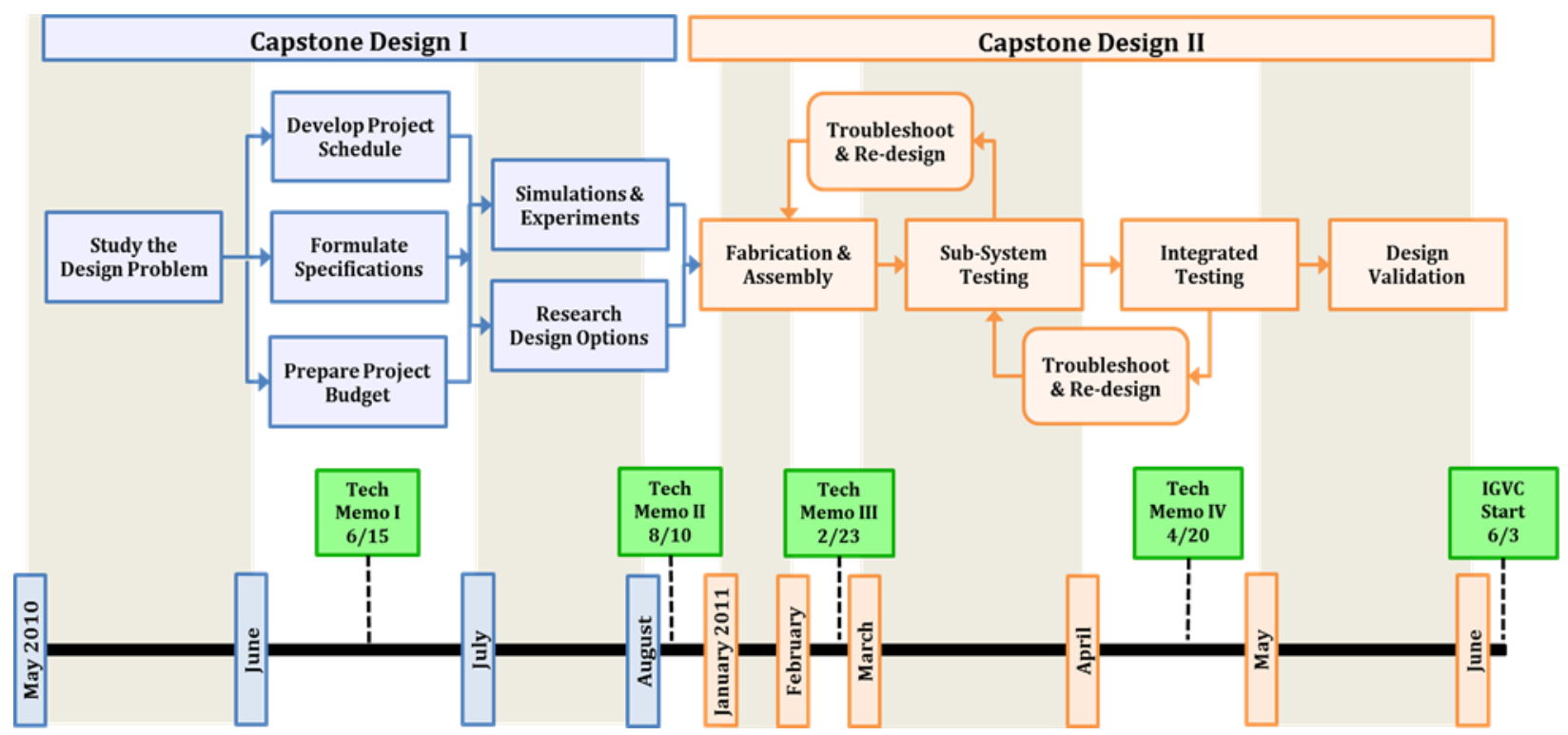

Figure 2: Design process and major milestones

\section{Team Organization}

Like any professional project, Capstone Design projects require establishment of a functional leadership hierarchy and allocation of duties and responsibilities. For the 2011 IGVC project, the team was divided into four sub-teams: one each responsible for sensory equipment and systems, programming and communications, structure and motion, power. Team members were assigned to sub-teams based on academic major and personal preference. A team captain was appointed to administer sub-team leaders, preside over team-level events, and serve as a liaison to sponsors and IGVC officials. Sub-team leaders were responsible for managing day-to-day operations and coordinating the efforts of individual team members. For consistency, the team captain and sub-team leaders remained the same for the entire project. The project organizational structure can be seen below in figure 3 .

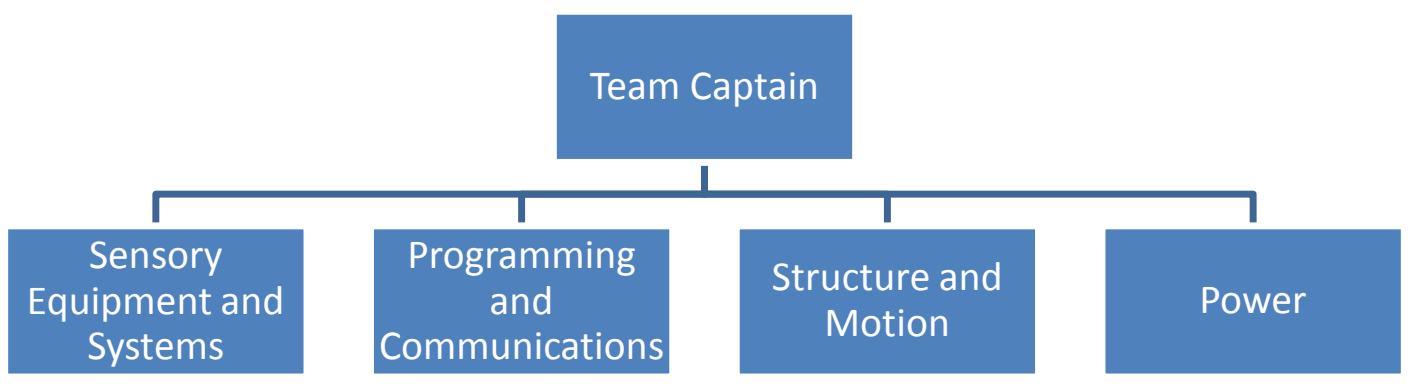

Figure 3: Design team organizational structure 


\section{Course Requirements and Team Practices}

Team members were required to formulate a set of independent learning objectives. These objectives, which were to be both measurable and achievable, enabled students to focus on areas of personal interest while providing the instructors with a supplemental means of assessing student performance. Including team meetings and related course instruction, students were expected to devote an average of ten hours each week to the project (about the amount of time a student could expect to spend on a three-credit engineering course). Students were required to document their work in engineering notebooks following the same standards applied in professional engineering practice. Notebooks were reviewed on a weekly basis by instructors to evaluate the progress of the project and the level of contribution of each student.

During the course of the project, team members prepared four technical memos detailing their individual contributions. Two of these reports were written in the summer design phase, and two in the spring build/test phase. These reports were intended to serve not only as an assessment tool but also as a resource for future IGVC teams. The first technical memo provided documentation of each member's research and planning and was concluded by a recommendation aimed at shaping the project specifications or vehicle design. In the second technical memo, a detailed review of design decisions was presented, accompanied by the analysis and simulation that was used to come to the final decisions. The third report discussed the progress of the construction of the robot and included a plan for the completion of systems integration and design validation. The fourth and final report documented the conclusion of the project and contained a reflective section in which team members conveyed lessons learned and recommended design improvements to the incoming design team.

The team adopted a set of practices which systematized the design process and aided in achieving consensus on design decisions and assured final product quality. For instance, all major design decisions were presented by respective sub-teams to the entire IGVC team and faculty advisors for approval. These presentations included a disclosure of cost, risk, and benefit, as well as incidental consequences upon other design attributes. Throughout the project, team members remained in frequent contact in order to keep one another appraised of sub-team progress and communicate all setbacks that impacted the project schedule.

During the course of the design, analysis, and fabrication process students from computer, electrical, and mechanical engineering programs worked together under the supervision of the faculty. The intelligent ground vehicle was a multi-disciplinary project which was divided into sub-teams such as sensor and camera, electrical power, navigation, and structure and motion. All sub-team members had to talk to members of other sub-teams to make sure that their design was coherent with others and met overall objectives. For example, structure and motion team needed to communicate with sensor and camera team to minimize vibrations and locate optimum sensor positions. Navigation team needed to talk to structure and motion team to understand the maximum speed and turns that the vehicle could handle. Navigation team also talked to sensor and camera team to understand the sensor outputs and to finalize the mapping. Power team needed to work with other sub-teams to understand the total power consumption for the vehicle and optimize the distribution. This inter-disciplinary communication was open and continued throughout the year. Students were able to appreciate other engineering perspectives and understood the need for multi-disciplinary teamwork to build a successful engineering project. 


\section{Engineering Design Process}

\section{$\underline{\text { Research and Planning }}$}

Defining a comprehensive set of vehicle performance specifications was paramount during the research and planning phase and proved to be an iterative process involving lengthy discussions and deliberations. The ultimate purpose of the specifications was to ensure that the vehicle could perform all intended functions while satisfying competition and safety rules. The majority of the specifications adopted by the structure and motion sub-team were derived directly from rules prescribed by the IGVC officials committee [4]. Other specifications were established to provide the vehicle with features that would facilitate systems integration, maintenance, and transportability. The finalized list of specifications of the structure and motion sub-team were as follows:

- Tank style, differential steer track system with zero turn radius capability

- Passive suspension system

- Gross weight of 200 pounds or less

- Target vehicle dimensions: 3 feet long by 2 feet wide

- Battery life sufficient for 30 minutes of continuous operation

- Maximum speed of 10 miles per hour

- Ability to transport a 20 pound payload of size 8 in $x 8$ in $x 18$ in

- Capability to climb surface grades up to $15 \%$

- Non-welded frame with removable peripheral structures

Once the list of general specifications had been completed, the structure and motion sub-team explored different technologies and design options. The team applied classical mechanics equations, as governed by these specifications, to begin designing vehicle components. The sub-team estimated various equipment parameters including motor power, battery ampere-hour rating, and strength requirements for structural components. These initial estimates provided a convenient frame of reference from which to begin preliminary equipment and design selection.

Components and materials identified as viable options were then scrutinized using more detailed analysis techniques such as finite element studies and simulated operation through dynamic modeling. This model provides information to sensor and camera and navigation sub-teams regarding vehicle speeds, turning restrictions, and stopping distances. This enabled the other sub-teams simultaneously to refine their own respective specifications for required sensing distances and system latencies. As the design evolved, the physics equations governing vehicle performance characteristics took on greater complexity. Three dynamic models were created to numerically prototype the response of the robot; a set of movement models describing linear motion and zero-point turn dynamics were created in addition to a suspension model. These movement models were created to give the programming sub-team more accurate vehicle limitations on different surfaces and grades. Unfortunately, without friction data from a physical prototype these models were not very useful for implementing motion control algorithms, however, they remained useful for validating adequacy of prospective components. 
The team budget contained three cost categories which would each amount to a vehicle that satisfied the specifications: low, middle and high pricing estimates. The higher priced items would offer convenient or useful features surpassing specification requirements whereas the lower priced items did not leave much tolerance between the expected performance and the specifications. The structure and motion sub-team projected budget ranged from $\$ 800$ at the low end to $\$ 4000$ on the high end. The sub-team's final expenses totaled nearly $\$ 3000$, which accounted for the majority of the net project costs. The high price tag of the structure and motion sub-team's systems was a consequence of the custom designed frame, pivot-intensive drive system and suspension system as well as the numerous electrical components used for energy distribution and signal routing.

\section{$\underline{\text { Experimentation }}$}

From the first day of the project, the team leadership stressed the importance of testing and experimentation. This was in great measure a response to the experience of the 2010 team, which had issues stemming from their lack of outdoor testing. The preliminary round of experiments was performed on individual components in order to obtain empirical performance data to supplement simulation and design analysis. Sub-system and integrated testing were then done for troubleshooting and validation purposes. Some of the experiments which were performed in the first semester were:

- Determining Motor Parameters - In order to simulate operation of the motors in Simulink [6], the DC motor's parameters had to determined. The parameters whose identification was required included armature resistance, $R$; motor inductance, $L$; no load speed $(\omega)$; no load current $(i)$; and the velocity constant, $K_{v}$. Resistance was determined by taking an average of resistance readings measured over a wide range of rotor positions. The no load parameters $\omega$ and $i$ were measured while applying maximum voltage $(V)$.

Next, $L$ was determined by performing a low voltage alternating current (AC) test while measuring the impedance $(Z)$. $L$ was found using the equation below:

$$
L=\frac{\sqrt{Z^{2}+R^{2}}}{2 * \pi * \text { frequency }}
$$

The no load speed, no load current, and $R$ were used to determine $K_{v}$ as follows

$$
K_{v}=\frac{\omega}{v-i R}
$$

With the $K_{v}$ known, the torque $\left(K_{t}\right)$ and back $\operatorname{EMF}\left(K_{e}\right)$ constants were found simply by applying the following relation:

$$
K_{t}=K_{e}=\frac{1}{K_{v}}
$$

- Torque Testing - By applying the above motor constants, the sub-team was able to simulate motor transients and estimate torque outputs. In order to confirm the accuracy of these estimates, torque testing was performed by coupling the motor to a supported output shaft and pulley. The motor spun the pulley, which wound a cable with an attached load. The resultant torque was 
found by the basic equation for torque in terms of applied load $(F)$ and moment arm $(r)$, which was equal to the pulley radius.

$$
T=F r
$$

- Surface Friction Determination - Static and kinetic coefficients of friction were calculated on wet and dry grass as well as wood for different tread feet to verify the coefficients found through research. Since there were three different foot options, this test was important in determining which would be the best. The team had been considering notched rubber treads, a bare plastic conveyor belt material and the same conveyor belt material augmented with grip tape. The team settled on the bare conveyor belt because it was best for zero-point turns and its performance on grass and wooden ramps was acceptable.

- Spring Constant and Damping Coefficient - The two foot by three foot dimensions of the robot correlate to an approximate 1/7 scale M1 Abrams tank [5]. This is an unusual scale for remote control vehicles and personal off road vehicles, so the sub-team was unable to find springs with mounts that had published spring rates or dampers with damping coefficients. When springs and dampers arrived, the first thing the mechanical sub-team did was to calculate their spring rates $(K)$ and damping coefficients $(c)$. The springs were compressed using known force values $(F)$ and the resulting displacements $(d)$ were recorded. The slope of the plotted values was used to find $K$.

$$
K_{\text {spring }}=\frac{F}{d}
$$

The damping rates were found by recording the time $(t)$ required to compress the damper using a known force $(F)$ over a known displacement $(d)$.

$$
c_{\text {damper }}=\frac{t F}{d}
$$

These spring constants were implemented into the dynamic models and the damper's position was adjusted to acquire the optimal linearized damping rate for the spring rate and weight.

\section{$\underline{\text { Design }}$}

An early design decision to be addressed pertained to the ground contact system. Most IGVC competitors employ a wheeled system, due in part to the simpler control procedures that result. However, YCP used a treaded system in its inaugural year at IGVC, which made the robot stand out from a design standpoint. After research and discussion, a treaded ground contact system was chosen over a wheeled system for a few reasons. For one, the vehicle would need to operate under a variety of surface conditions and the soft, soaked fields at the 2010 competition made the team wary of a muddy course. Treads also provided for smoother ride characteristics at low speeds on rough surfaces such as grass which would benefit the sensors sub-team by providing a more stable platform for cameras and other sensing devices. 
The treaded system went through several iterations as space constraints arose, machining was considered and parts were priced. The 2010 design consisted of a commercially-available conveyor belt. A drive system was implemented via a female drive sprocket and a male conveyor (accomplished by attaching flanges to the conveyor belt). Problems with drive engagement arose in the 2010 system, so the team chose to go to a more common male drive sprocket and female industrial conveyor. The mechanical subteam decided upon using a male type drive and idler sprocket with a female type industrial conveyor manufactured by Rexnord. This combination allowed for simplicity and efficiency since a direct drive system could be implemented minimizing losses.

The decision to use the Rexnord tread system had other positive aspects - it allowed less complicated roadwheel and suspension designs, ultimately improving the maneuverability of the vehicle. The fully passive suspension system was designed to eliminate detrimental effects on the sensors and allow for more accurate sensor data. The first suspension design incorporated four identical roadwheel-spring assemblies as seen in Figure 4.

The problems with these individual roadwheel sub-assemblies were that there was a low factor of safety in the fatigued connection points in addition to no practical way to damp out oscillations within the system. This latter problem violated the team's specifications, and thus redesign was mandatory. The next design iteration employed a set of symmetrical rocker feet assemblies as seen in Figure 5. With this design, there was more room for damping mechanisms and improved tread tensioning as a result of the pivot action of the rocker foot serving to maintain adequate tread tension during spring compression. The springs also were aligned in a more favorable vertical configuration.

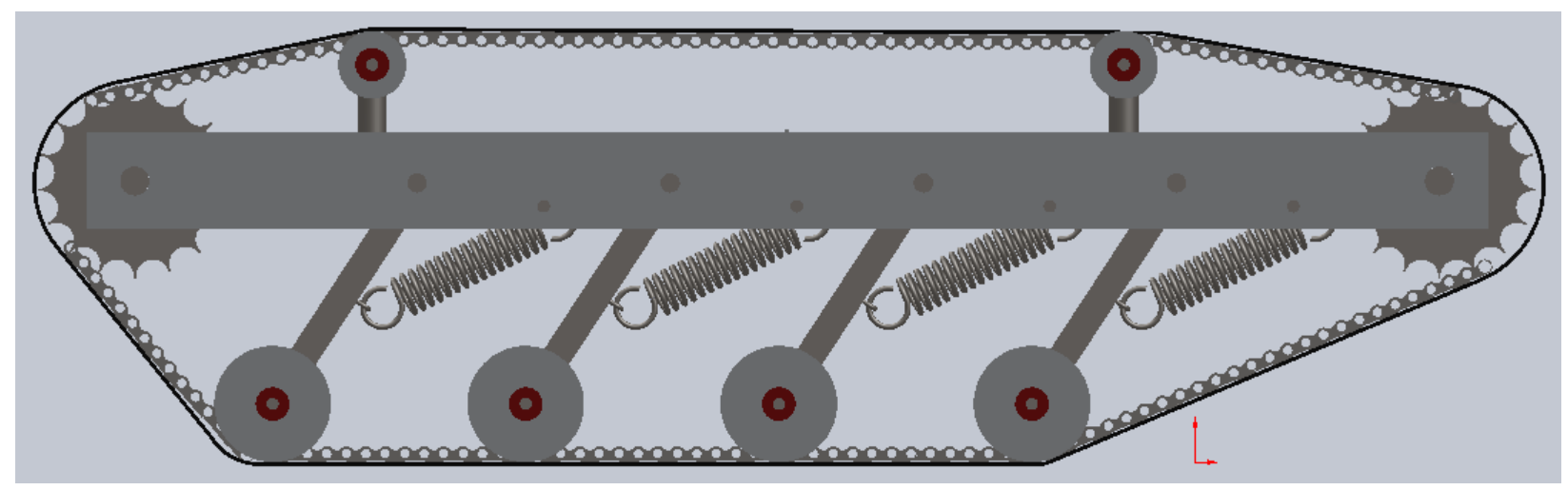

Figure 4: First iteration of tread and suspension systems

Though a passive suspension system was chosen, the mechanical sub-team was surprised to find difficulty in locating cost effective springs and dampers to fit the design characteristics. Coil springs were chosen from available spring-and-mount assemblies to reduce cost and save time. Industrial grade dampers were selected based on their cost, dimensions and expected damping rates. After the damping rate was determined, the dampers' position was modified to provide desirable damping rates.

Through the suspension design process, finite element analysis (FEA) was performed on critical parts to ensure thickness and material properties were sufficient. One of the parts which the team tested numerically was the rocker foot plate. Figure 6 shows stress analysis of the plate in steady state 
supporting $1 / 8$ of the robot's weight. These pieces ended up being galvanized steel because of the expected lateral loadings in zero point turns. The team had initially hoped to save weight in these parts, but the loading proved to make aluminum a poor material choice.

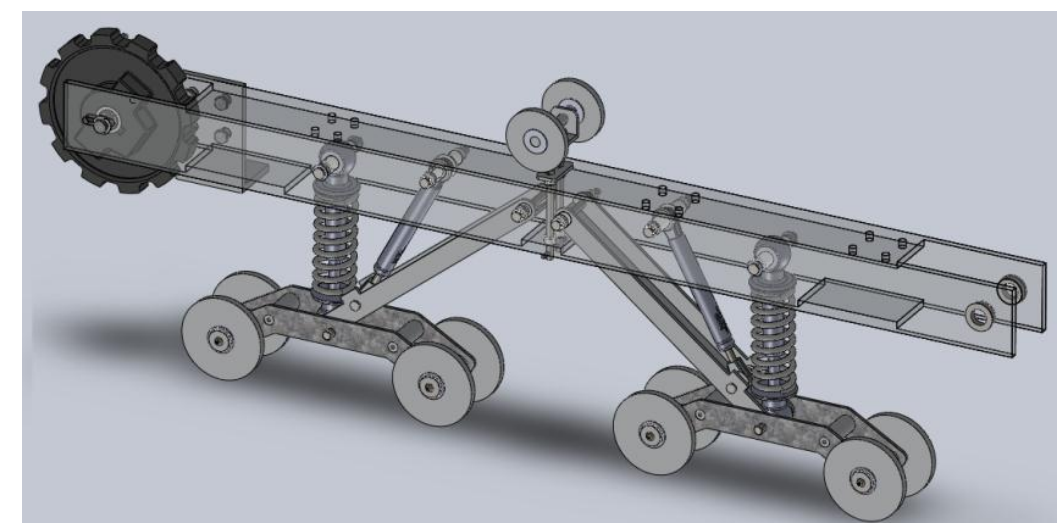

Figure 5: Final suspension design to accept Rexnord treads

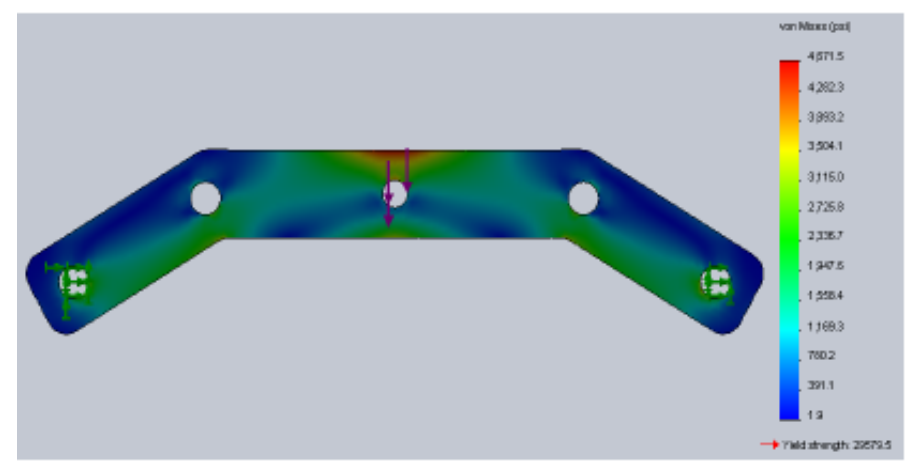

Figure 6: FEA on rocker foot plate to check hole placement and sharp corners from expected band saw cuts

A methodology consistent to that used for the suspension system was applied to the design of the frame. Thus the main areas of concern when designing the frame were weight, cost, adaptability and rigidity. To ensure that the tracked suspension system operated as designed, a rigid frame was critical. Three cross beams were implemented to ensure that relative motion between the two track beams would be minimized. FEA was also performed on the frame skeleton to determine its torsional rigidity. This was accomplished by constraining three corners of the frame and applying a vertical load to the fourth corner. This test showed that the frame structure was significantly more rigid than the suspension, meaning that the vast majority of motion due to ground irregularity would be captured in the suspension.

Adaptability was another important concern for the vehicle due to uncertainties with component dimensions and sensor placement. Having the ability to alter the location of various components was desirable to optimize space management. Adaptability drove the decision to bolt the structural members of the vehicle together rather than weld them. Had a member needed to be moved, the team could have simply performed FEA on the new hole pattern, drilled new holes, and moved the member to the new location. 
The team chose to make the camera tower and frame from aluminum, with the frame bolted together in order to provide adaptability in sensor placement and the camera tower welded to provide better structural rigidity. The bottom of the tower was constrained with sleeves allowing it to be removed easily. The tower's tripod design further minimized the deflection at the top of the tower, which was important because the camera and inertial measurement unit would be adversely affected by vibrations. These points were verified using FEA; the deflection at the top and the tower's natural frequencies were discovered via software as well.

\section{$\underline{\text { Simulation }}$}

Although the 2011 robot used a tread system like the 2010 robot did, there were significant differences in the structural and suspension designs. This made the 2010 robot a poor test bench for the 2011 vehicle; testing of the 2010 vehicle as a prototype would not have been informative for the 2011 design. Thus, the structure and motion sub-team used dynamic models to simulate the motion of the vehicle. The associated accuracy of the dynamic models was desired to increase efficiency but more importantly validate the design.

The first step in developing these models was to create a block diagram in Simulink [6] that represented the DC motor dynamics as seen in Figure 7. The motor parameters and constants were initialized using specifications for these various components, but were later adjusted to match those found in the experimentation phase. The model was set up such that the input to the system was armature voltage, which would be the actual control handle on vehicle motion by way of pulse width modulation using a motor controller. Initially, certain load parameters such as load torque $\left(\mathrm{T}_{\mathrm{L}}\right)$ and viscous damping (c) were approximated.

Next, the team attempted to model the treaded vehicle's slip as accurately as possible. The literature offered several different methods of estimating slip and many required empirical constants. So that the model made by the team would be better understood, the team developed an approximation through a combination of static, kinetic and viscous friction forces. At the same time, more complex subsystems were created in the Simulink model to account for the actual components associated with the propulsion system. The tread, sprocket and wheel masses were accounted for by introducing equivalent inertias to the system, adding resistance to the drive motors. A function for the load torque that was dependent upon situational factors as well as properties of the vehicles design took into account frictional losses in bearings and tread pivots, mass of the vehicle, and changing forces due to slope of the terrain.

After the motors and motor controller were specified, the linear motion and zero-point turning dynamic models replicated the abilities of a physical robot with the exception of accurate rolling resistance and friction forces imposed by the drivetrain's bearings. The dynamic models were as complete as they could be until empirical data was available for friction values. In the meantime, assumptions were made based on system responses such as maximum speed and zero-point turning rates. To predict the maximum and minimum linear accelerations of the robot, a ramp input signal was created to apply 24 VDC to the theoretical motors where the slope was based on the minimum and maximum times for full voltage to be reached by the motor controller used [3]. The system responses from this data allowed the team to predict both power consumption and distance required to stop. This data was useful for the team, because they were able to verify the ability to stay under the $10 \mathrm{mph}$ speed limit while still finishing the course in less than 5 minutes. 


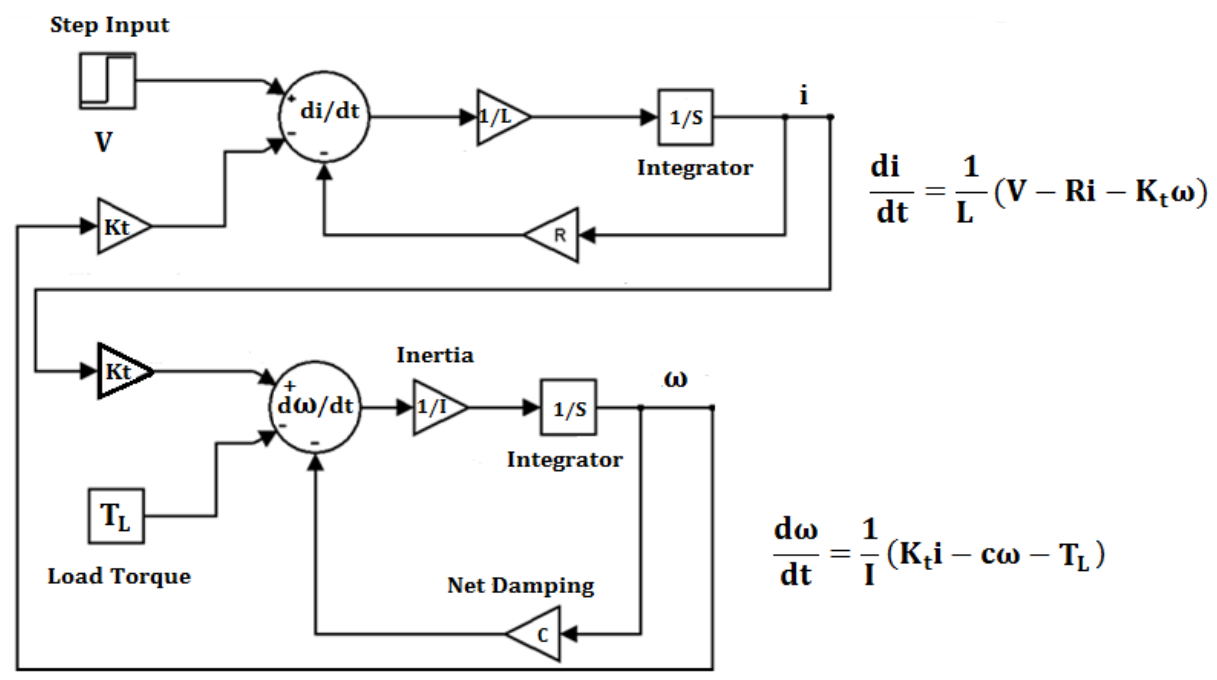

Figure 7: Simulink block diagram of coupled motor dynamics equations

The zero-point turn model accepted the same voltage input as the linear model. The change in motion required that the manner in which friction was applied by the treads be modified to use a viscous component. The zero-point turn model was useful in verifying the robot's ability to meet that particular specification. The model showed the robot turned at a reasonable rate without requiring full power. The model also showed how much more power was necessary to keep the robot turning about a point compared to travelling linearly at a constant velocity. These rotational and linear power vs. speed results are shown in Figures 9,10 and 11. This justified the benefit of working toward including swept turning; however, the selected batteries were designed to have the capacity to make it through the course in inefficient linear movements.

The third dynamic model was the suspension model which went through multiple iterations as the structure and motion sub-team converged on a final design. A quarter vehicle model was generated to verify the coil springs and dampers did not deflect past the suspension's limits and to determine the proper damping rate. Figure 8 shows the Simulink response used to validate the spring and dampers were performing within known specifications.

Figure 8 simulates a single rocker assembly travelling over something resembling debris or a speed bump but other road surfaces and inclines were simulated to verify the spring and damper rates. Instead of looking at the voltage and current requirements in the suspension model, the structure and motion subteam was more concerned with determining how the robot handled changes in road variation. This was accomplished by rearranging the equations so ground height was an input.

\section{Electrical Design}

The power system of the vehicle was broken down into two separate subsystems, the motor drive system and the auxiliary, or logic power system. The auxiliary power system was designed to supply power to every component on the vehicle other than the drive motors. This includes the GPS, LIDAR, wireless EStop receiver, safety light, and motor controller logic power. All of these devices were run off of a 12 VDC supply. The main reason for having two power sources was due to the DC motor drive creating a current spike when they were in a transient state. 
In order to find the required capacity of the motor drive batteries for a minimum runtime of 30 minutes the transient and steady states of the vehicle were analyzed. It was important to know that the motor drive batteries being used were going to be lead acid because they have special discharge curves associated with them. For this analysis Figures 9 and 10 were analyzed. The four different curves on Figure 9 represent different acceleration times or different amounts of time until the terminal voltage of the battery/batteries could be met. For the dynamic models shown in Figures 9 and 10, a 24 V, 450 W motor was analyzed.

When determining the battery capacity for the transient state the worst case scenarios were taken into consideration. For the acceleration transient state shown in Figure 9, the worst case scenario was the fastest acceleration time allowed by the motor controller: 0.085 seconds. Figure 9 is only representing one of the two motors so current readings have to be doubled.

Figure 9 shows that after 2.0 seconds the steady state current is reached at $5 \mathrm{~A}$. In between the first time interval, $0-0.25$ seconds, there is a current spike of $144 \mathrm{~A}$. This value is only for a matter of 0.125 seconds. The average amount of current drawn over the two second period for transient acceleration was found to be $35 \mathrm{~A}$. The current drawn during a zero point turn shown in Figure 10 was analyzed the same way as the forward acceleration.

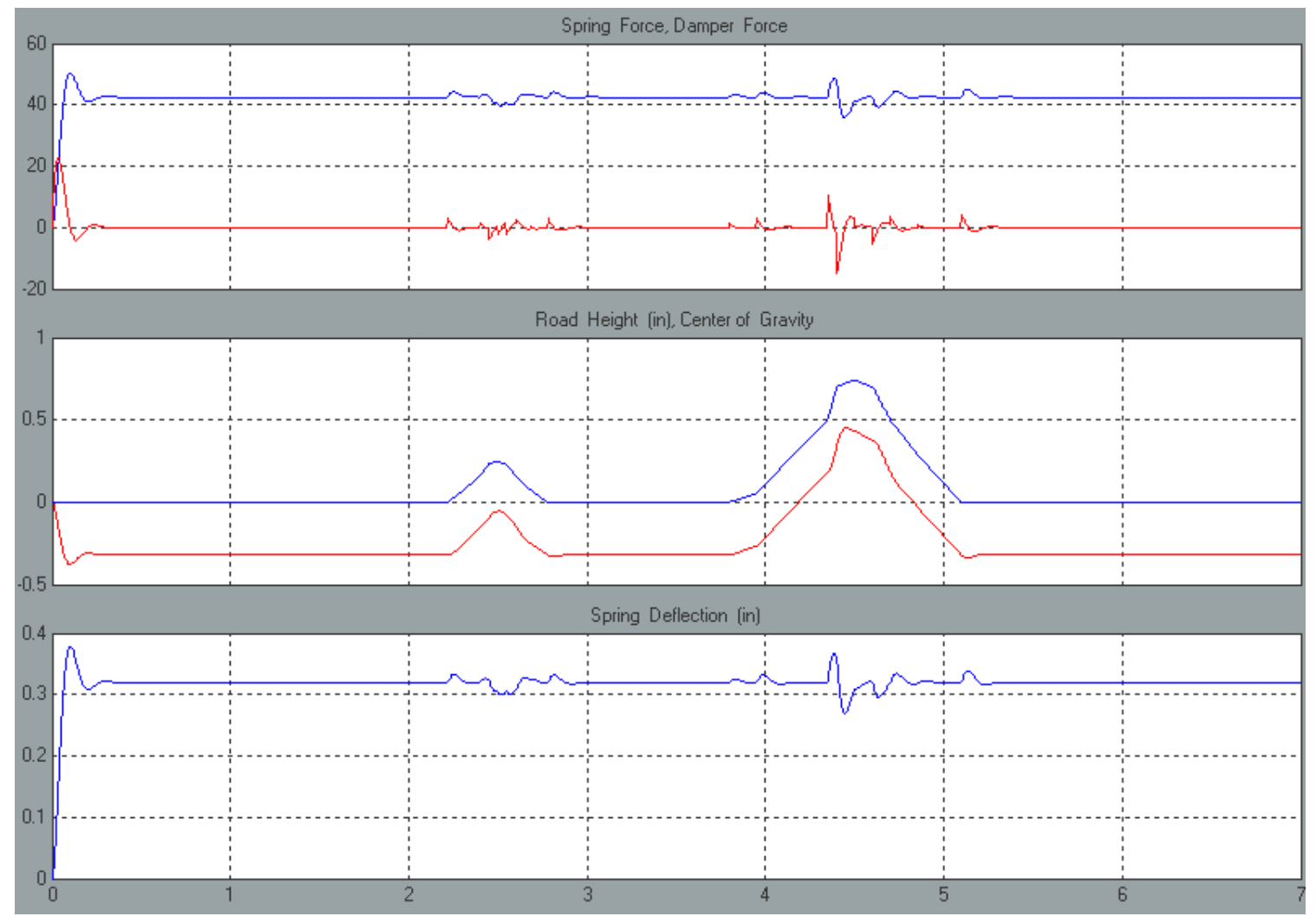

Figure 8: Simulation of spring and damper response for 1/4" and 3/4" road variation peaks

Zero point turning transient state currents also reached steady state after 2.0 seconds as shown in figure 10 . This model assumed maximum acceleration of the motor. The average amount of current drawn over this two second period of the zero turn transient state was found to be $57 \mathrm{~A}$. There is a larger amount of average current over the turning transient state than the forward acceleration transient state. 


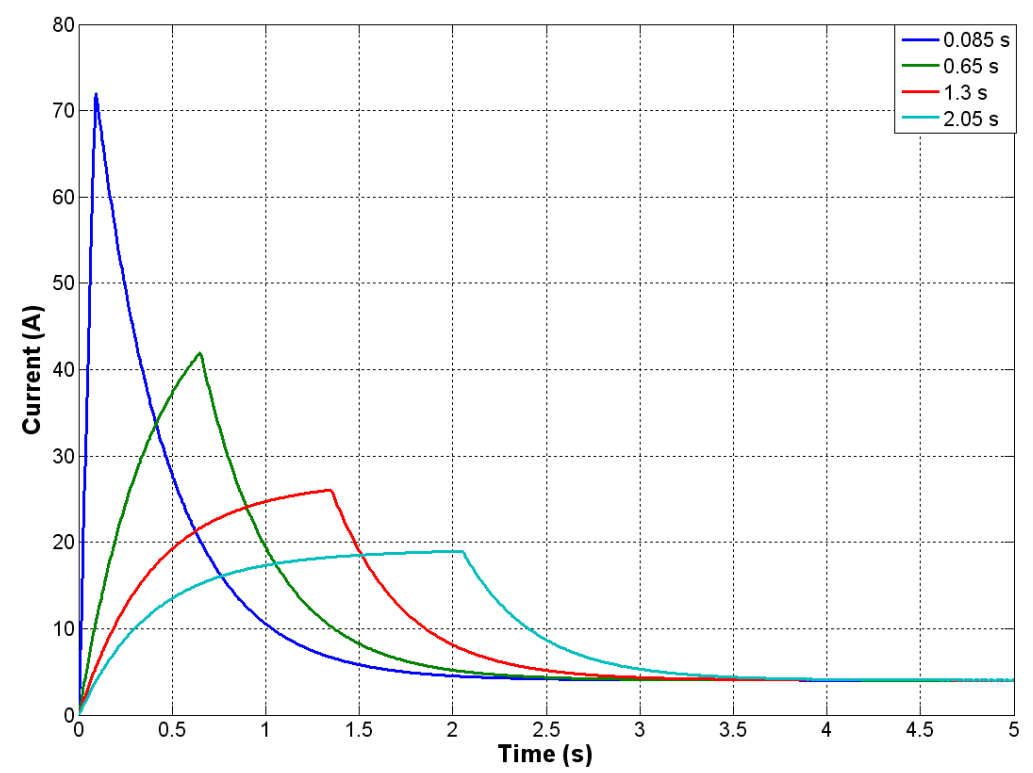

Figure 9: Current magnitudes and acceleration time for various dynamic testing

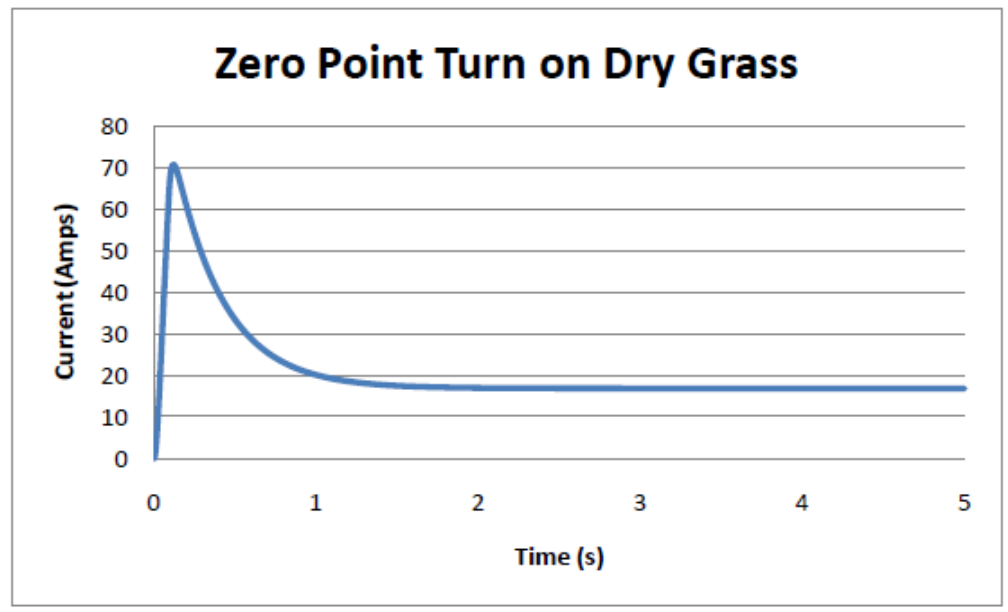

Figure 10: Current magnitudes and acceleration time for zero point turning of the vehicle

Through information gathered from other 2010 team members and by observing other schools' vehicles competing, it had been determined that the vehicle would only be in steady state operation $55 \%$ of the time while running the course. This left $45 \%$ of the time for transient operation. Of the $45 \%$ it would be turning for $20 \%$ of the time and undergoing forward acceleration the other $25 \%$ of the time. The specification for run time is a minimum of 30 minutes. Calculations considered C-rate of the battery, transient turning and acceleration times, and steady-state time to design the battery size. Two $12 \mathrm{~V}$ lead acid batteries with a capacity of $28.50 \mathrm{AH}$ were found to be enough to supply required energy for the project.

Considering all aspects of the design, two $12 \mathrm{~V}$ Absorbent Glass Mat (AGM) sealed lead acid batteries connected in series to supply two $450 \mathrm{~W}$ brushed DC motors with 24 VDC. As per the required high capacity, lead acid battery technology was the only battery technology that fit within the team's budget. AGM lead acid batteries were selected for their ability to be placed in any position without leaking. The motor drive batteries were connected to a dual channel Roboteq HDC2450 motor controller. This controller supplied the appropriate amount of power to the drive motors depending on the decision making sub-teams' desired speed and direction. 
US Digital 2500 CPR optical encoders were used to send feedback to the motor controller for closed loop operation.

\section{$\underline{\text { Fabrication }}$}

The vehicle was designed to be as simple as possible because all of the machining was done in the school's machine shop with the exception of the camera tower. When the team members were freshmen, they were required to take two project-oriented classes to provide basic skills in machining and fabrication of components.. As freshmen, the shop supervisors had a small project such as a pen or YCP keychain to let students work on the more common machines in the shop. After about a month of introduction to the machine shop, the students had designed their projects and started machining and assembling. This was a valuable resource for the engineers when they reached their senior year and started designing the robot. The brief machine shop experience, in addition to the students' co-op experiences in manufacturing environments, helped the students to understand how manufacture relates to design. This reduced the number of changes since the students considered fabrication issues when completing their design The structure and motion sub-team's advisors pursued an ambitious timeline in order to allow for adequate time to test the prototype. This required the team to complete the physical robot as quickly as possible. Through the fabrication process, there were very few design changes, some of which included sensor mounts for added adjustability. The majority of the parts were machined manually but there were a few parts made on the CNC lathe with the help of a shop supervisor.

\section{$\underline{\text { Troubleshooting and Re-design }}$}

As the sub-assemblies came together, they were tested to verify the design was functional. With the robot coming together without critical issues, it eventually came time to test the robot with a remote control. There were no issues when testing the robot indoors on a smooth concrete surface but when it was tested on the grass, some issues were encountered. There were also issues which arose from continued use and wear:

- $\quad$ Tread de-railing

The treads would de-rail in midst of a zero-point turn on grass due to the design of the treads; the tread rotating in reverse would de-rail nearly every time. Furthermore, the treads unexpectedly arched at the center of the robot which promoted misalignment. The first re-design to this arching issue was to drill out the tapered coupling joints between the tread feet and tighten them with spacers. This helped at first, but as the robot's weight increased with the addition of more weather and electronics protection, the de-railing issue remained. The final solution to this problem was to move the upright tensioner to the bottom of the suspension frame acting as a fifth road wheel, eliminating the de-railing problem.

- Encoder issues

There was a problem with electrical interference from the motors in addition to mechanical misalignment issues resulting from axial forces on the output shaft which made the encoders return incorrect values to the motor controller. To eliminate these 
problems, the optical readers were re-positioned, the encoder discs were spaced more carefully and spacers were added to the motor output shaft to reduce axial forces on the motors' bearings.

- Bearing issues

Idler sprocket bearings were initially radial ball bearings spaced about an inch and a half from each other. After press-fitting them into the idler sprocket and pressing in the axle, there was non-concentricity which added a significant amount of resistance to the bearings. The ball bearings were replaced with individual needle bearings to eliminate this problem.

\section{$\underline{\text { Design Validation }}$}

Once the structure and motion sub-team eliminated the problems with the robot, they performed tests to compare the performance with the specifications. The weight was one of the first things looked into; the gross weight of the vehicle and payload ended up being $195 \mathrm{lbs}$ which was $25 \mathrm{lbs}$ more than the initial design. This difference in weight was due to the addition of weatherproofing, wiring and magnetic interference reduction. Even at this weight, the robot was able to climb the maximum incline outlined in the IGVC rules [4], surpassing it by a factor of about 4 on dry grass. There were also acceleration tests to determine whether or not slip was going to be a problem; the robot ended up holding its traction so well that while stopping from full speed on dry grass it pivoted about the front rocker foot to the point where the back rocker foot lifted up off the ground. There were also maximum speed tests done on asphalt and grass which resulted in a top speed of $7.5 \mathrm{mph}$.

One of the other validation tasks was to correct the assumed friction values in the dynamic models. The linear motion and zero-point turn dynamic models were adjusted to fit empirical data once the constants associated with the weight change were modified. No-load data was used to determine the viscous friction constant from the combined drivetrain losses. This was done by gathering electrical power data and angular sprocket velocity while the treads were suspended. The only empirical modification to the linear model was to correct the rolling resistance of grass. The empirical data and the modified dynamic model's results for linear tests are displayed in Figure 11. The empirical data was calculated by querying measurements from the motor controller. Considering the only parameters which were not calculated were the friction values, these were the only values that were changed. It is likely the current did not spike as high as it should have because of measurement errors when determining motor constants.

In the zero-point turn model, the same viscous friction constant from the linear model was used to numerically duplicate the same robot. There were a few modifications to this model, one being the kinetic friction of the slipping tread, the second being the addition of a viscous friction moment between the pivoting robot and the grass, and finally a scaled static friction moment about the pivot point. The static friction moment had been approximated as a distributed triangular load applied to each quarter of the tread, which was then multiplied by half the vehicle's width. This approximation was allowable because the center of gravity of the vehicle was near the geometric center. With a 2-plane symmetric ground contact system like Sparta's, having the center of gravity was within a few inches of the geometric center provided a known pivot point. This distributed approximation turned out to be too low, and therefore it was scaled by approximately 1.5 times to match the empirical data in addition to a viscous friction 
moment. The empirical data and the modified dynamic model's results for the zero-point turn tests are displayed in Figure 12. The motor current in the dynamic model is significantly different from the empirical data, likely due to the unchanged friction values inherited from the linear model.

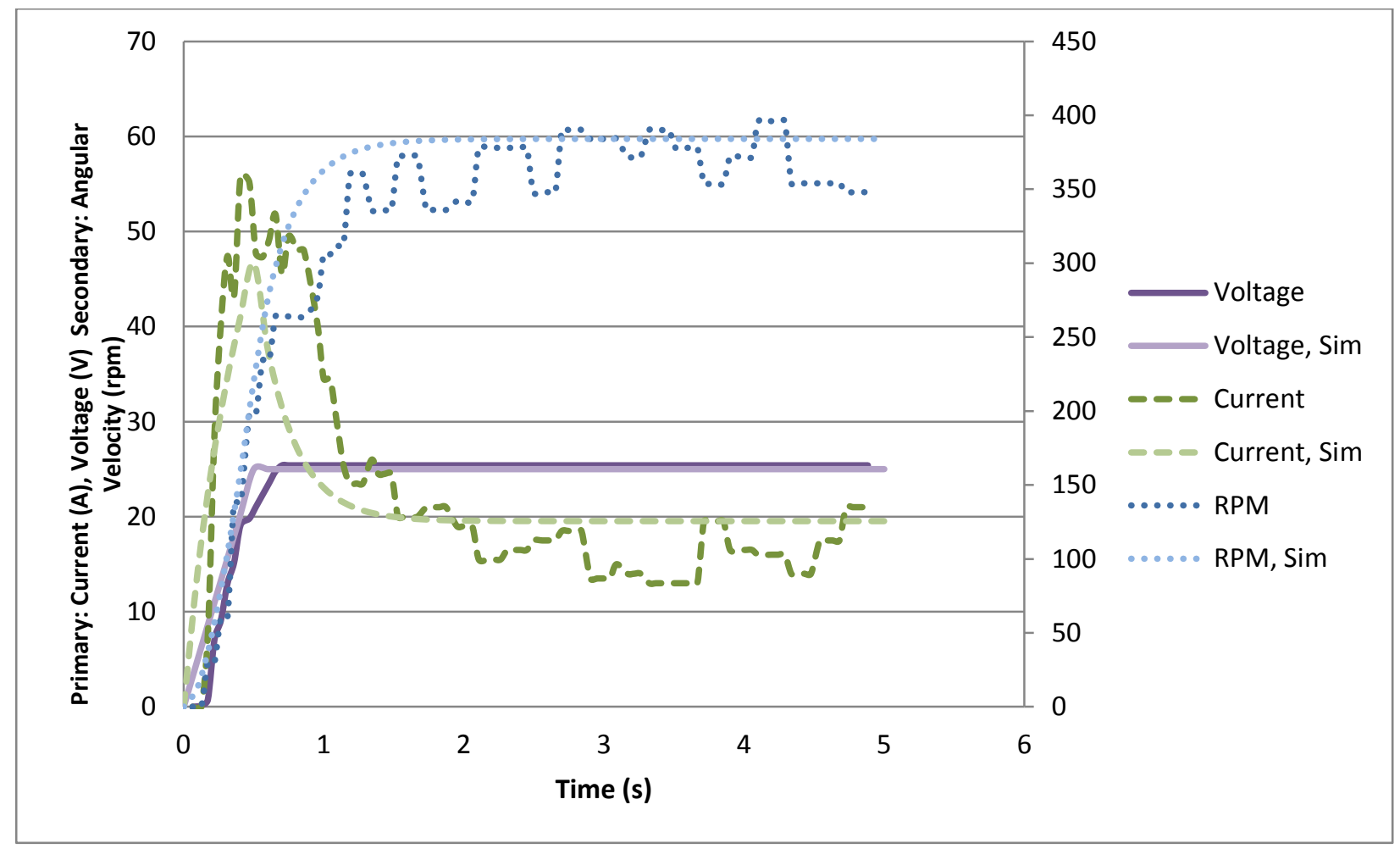

Figure 11: Linear motion data comparing simulated values to empirical values

Modifying the system parameters in the dynamic models was successful with the exception of motor current. It is possible that the motor controller had difficulty measuring current in the motors in the case of the linear model, but when the zero-point turn model is considered this seems unlikely. One possibility is that when the motors experience more resistance, the idealized models have difficulty estimating the back EMF of the motor because the simulated curves follow the general trends of the empirical data but only match when accelerations decrease.

\section{Outcomes Assessment}

The Capstone Design course, being a culminating experience for the senior students in the engineering programs, is used to assess many program outcomes required by ABET, the accrediting body for engineering programs. While the work of the students on this project was evaluated in light of all of these applicable outcomes, this paper will focus on the implementation of assessment for outcome (c), which requires students to exhibit "An ability to design a system, component or process to meet desired needs within realistic constraints." The remaining outcomes were assessed in a manner similar to what is described in this section. 


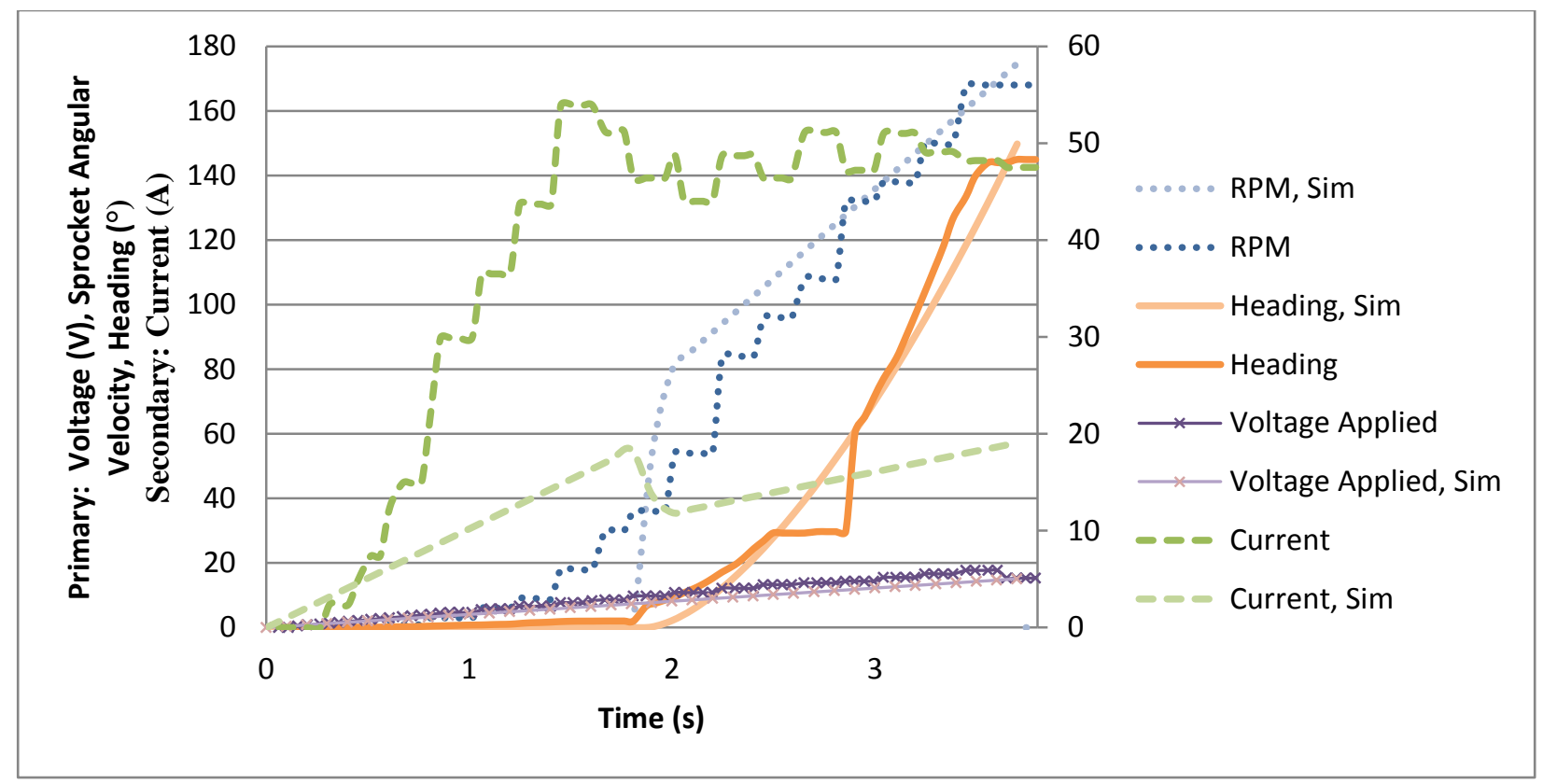

Figure 12: Zero-point turning data comparing simulated values to empirical values

Students in the Capstone Design course are asked to produce several deliverable items to the faculty that may be used to help assess program outcomes. One of these is the prototype itself - a working prototype necessarily implies that students can design the system or component required. However, assessing individual student contributions in the context of a single working device is problematic. For that reason, the prototype itself is not used as an assessment metric for students' individual learning.

As the students develop, build and test the prototype, they are required to provide several more individual markers of progress. First, students maintain an engineering notebook in which they are required to document their work for both semesters of Capstone Design. These notebooks, when maintained according to the guidelines handed to the students at the first class meeting, include initial background research, hand sketches of schematics for a design, planning for prototype testing, samples of analysis and results of testing, and notes regarding future design iterations. The faculty reviews these notes on a weekly basis, allowing student progress to be guided more readily and giving the faculty a sense of the level of analysis being brought to bear on the design problem.

Students are also required to provide four technical memos, two per Capstone Design semester. These reports provide a progression of the students' design work, due to the reports' timing within the overall project. The first report typically summarizes research work and presents initial design thoughts. The second finalizes the component or subsystem design, with justification for the decisions made and some plans for fabrication and further testing. The third report provides further discussion of testing and manufacture, often with detailed drawings and photos of the finished product. Lastly, the fourth report summarizes the overall design and describes the manner in which the design may have evolved in response to results of the testing described earlier in the course sequence. Students are given written assignment descriptions that ask for them to address these various points on each report, allowing the faculty members to look for certain aspects of the overall design work at different times in the two-course sequence. 
In order to evaluate work for program objectives, the engineering programs at YCP have each established rubrics for each objective. Figure 13 shows the rubric used for outcome (c) by the Mechanical Engineering program; the Electrical and Computer Engineering program uses a slightly different rubric with the same overall targets. There are five performance indicators at the left-hand column that are used to inform the overall assessment of the outcome. The way the technical memos are assigned to the students precludes any one report from being capable of assessing all five performance indicators simultaneously. The rubric is applied differently for each of the four reports. The first report, being an initial description, is evaluated heavily on specifications and candidate solutions, with some weight given to the first stages of analysis of various solutions. The second report presents a final candidate design; this report is evaluated for the quality of analysis used in examining solutions and in the rationale used in determining the final design candidate. The third report usually has some more virtual testing and design tweaks, and is thus used to address the quality of analysis a second time, the rationale in choosing the final design and the students' ability to modify the design in light of testing. The final report is expected to have live testing of the prototype, and is thus evaluated heavily for design improvements. This includes the thought process that drives the tests performed and the systematic nature of the overall evaluation. The combination of notebooks and reports allows the Capstone Design instructors to address the way in which the students approach design as the work is happening (mainly through the notebooks) and in a summary form (through the reports). This allows deficiencies in individual students' work to be addressed prior to the end of the course, and allows the outcomes to be assessed several times through the two-semester course sequence.

To fix ideas, note that the foregoing discussion regarding the design and evaluation of the ground contact system was also found in various technical memos written by the students themselves. The variety of solutions considered (including wheeled systems) led to an evaluation level of "Exceeds Expectations" for that criterion of the rubric. Overall, the quality of design work led to two of the four mechanical engineering students being deemed to have exceeded expectations, while the other two mechanical engineering students met the faculty expectations. The electrical engineering student on this team also met expectations.

\section{Reflections and General Course Grading}

From an instructional perspective, there are several lessons to be learned from having taught such a course using a large-scale competitive project. One of these is to assign students to specific tasks early in the process, and with set deadlines. Through several iterations of this course, the approach taken has converged on faculty taking a managerial role in the process. That means setting high-level component and software completion deadlines and reinforcing the budget. Some students are selected for team leadership positions, based on technical ability, interest and faculty knowledge of the students. This last metric is viable at a small institution like York College of Pennsylvania, which has five full faculty each in the mechanical and electrical/computer engineering programs. With this faculty size, it is certain that some of the faculty members teaching Capstone Design will have worked with all of the students in a prior course at some point in the students' careers. At a larger institution, selection of student leadership would likely have to rely upon student self-selection reinforced by impressions that faculty colleagues have of students from other courses. 


\section{(c): An ability to design a system, component or process to meet desired needs within realistic constraints}

Assessment Metric:

\begin{tabular}{|c|c|c|c|}
\hline Indicator & Below Expectations & Meets Expectations & Exceeds Expectations \\
\hline $\begin{array}{l}\text { Identifies and } \\
\text { defines appropriate } \\
\text { specifications } \\
\text { Possible points: }\end{array}$ & $\begin{array}{l}\text { Specifications are inadequate, not } \\
\text { reasonable and/or not considered } \\
\text { Point Range: }\end{array}$ & $\begin{array}{l}\text { Specifications are noted and are } \\
\text { reasonable for desired application, with } \\
\text { some missing or extraneous paramet ers } \\
\text { Point Range: }\end{array}$ & $\begin{array}{l}\text { Specifications are noted and are } \\
\text { reasonable for desired application } \\
\text { Point Range: }\end{array}$ \\
\hline $\begin{array}{l}\text { Brainstorms } \\
\text { candidate solutions } \\
\text { Possible points: }\end{array}$ & $\begin{array}{l}\text { Identifies few possible alternatives or } \\
\text { solutions inappropriate for design } \\
\text { Point Range: }\end{array}$ & $\begin{array}{l}\text { Arrives at many possible design } \\
\text { alternatives, with few creative or } \\
\text { especially innovative options }\end{array}$ & $\begin{array}{l}\text { Arrives at many possible design } \\
\text { alt ernatives and has creative or } \\
\text { innovative options, even if these options } \\
\text { are not feasible to implement } \\
\text { Point Range: }\end{array}$ \\
\hline $\begin{array}{l}\text { Evaluates multiple } \\
\text { appropriate design } \\
\text { alternatives }\end{array}$ & $\begin{array}{l}\text { Considers to o few candidate designs } \\
\text { and/or has little or no analysis and/or } \\
\text { has selected inappropriate design } \\
\text { alternatives } \\
\text { Point Range: }\end{array}$ & $\begin{array}{l}\text { Considers adequate candidate designs } \\
\text { with incomplete analysis or discussion of } \\
\text { alternatives } \\
\text { Point Range: }\end{array}$ & $\begin{array}{l}\text { Considers adequate candidate designs } \\
\text { with thorough analysis } \\
\text { of each } \\
\text { Point Range: }\end{array}$ \\
\hline $\begin{array}{l}\text { Selects and defends } \\
\text { appropriate final } \\
\text { design } \\
\text { Possible points: }\end{array}$ & $\begin{array}{l}\text { Rationale for selecting design is } \\
\text { unreasonable and/or explanation has } \\
\text { severe errors or omissions } \\
\text { Point Range: }\end{array}$ & $\begin{array}{l}\text { Rationale for selecting design is } \\
\text { reasonable, but explanation has minor } \\
\text { errors or omissions } \\
\text { Point Range: }\end{array}$ & $\begin{array}{l}\text { Rationale for selecting design is } \\
\text { reasonable and is explained thoroughly } \\
\text { Point Range: }\end{array}$ \\
\hline $\begin{array}{l}\text { Improves design } \\
\text { systematically in } \\
\text { response to testing } \\
\text { Possible points: }\end{array}$ & $\begin{array}{l}\text { Design is not tested and/or test results } \\
\text { are not used to improve performance } \\
\text { Point Range: }\end{array}$ & $\begin{array}{l}\text { Some testing is used to improve design; } \\
\text { testing may not be syst ematic or } \\
\text { organized }\end{array}$ & $\begin{array}{l}\text { Systematic test ing is used to evaluate } \\
\text { design performance and improve design }\end{array}$ \\
\hline
\end{tabular}

Figure 13: Sample rubric used by the mechanical engineering program at YCP for ABET outcome (c)

Assessment for ABET outcomes via competitive projects is difficult when left simply to the documentation that the competition may require. Thus, the faculty need to install mechanisms to allow for student work to be checked periodically. To that end, we have implemented a few methods to date:

- Weekly engineering notebooks, allowing faculty to check and enforce incremental progress

- Technical reports, allowing writing skills and the overall design/build/test sequence to be checked

- Milestones and deadlines, allowing the effectiveness of the individuals responsible to be assessed

This set of methods is continuously evolving as the Capstone Design course is started each year. For example, the milestones were implemented as a response to students coasting through the course or prioritizing other coursework to the significant detriment of the project. The methods above are also the metrics that inform the students' course grades, along with presentations to the faculty, the team and, on occasion, to industry representatives.

\section{Discussion and Conclusions}

Looking back on the experience, it is clear that the success enjoyed by the structure and motion sub-team was the result of several key practices: 
- Communication - Frequent and honest communication among sub-team members was perhaps the most important factor because it enabled the team to accurately gauge project situations and adapt accordingly.

- Accountability - Team members held each other accountable for completing assigned duties and responsibilities. Taking the initiative to enforce this measure internally ensured the timely delivery of the completed design and precluded the need for faculty to enforce project deadlines. It also strengthened teamwork and leadership skills.

- Quality Assurance - The sub-team maintained a commitment to quality through all phases of the design process. This discipline was particularly important during the fabrication and re-design phases, where adherence to tolerances and specifications translated into hundreds of man-hours constructing and repairing the robot.

The sub-team's final design proved to be effective in the field and was largely responsible for the team's favorable standing in the IGVC design competition. Specific aspects of the design enhanced the performance and marketability of the vehicle including:

- Track System - The innovative and performance oriented ground contact/suspension system was impressive to look at and provided the robot with a high degree of maneuverability, stability and traction.

- Modular Structure - The fastened frame and removable camera tower provided a robust platform for all other subsystems and sensors without compromising maintainability and transportability.

- Packaging - The overall fit and finish not only attracted positive attention but enhanced the functionality of the vehicle as well.

No design is perfect, and the structure and motion team's mechanical and electrical systems were certainly no exception. In hindsight, the sub-team recognized several areas where the design could be improved and communicated appropriate recommendations to the incoming YCP IGVC team.

- Vehicle Weight - Although the vehicle satisfied the maximum weight specification, a reduction in weight would improve the handling characteristics, longevity and transportability of the robot.

- Motion Control - Dynamic modeling was not utilized to its fullest potential. The turning and linear travel models could be used as a starting point for developing dynamics-based motion control algorithms.

Other than actual student grades and student course evaluations, there was very little formal assessment done for the IGVC capstone project. However, the faculty and students assigned to YCP's 2011 IGVC team agree that the project outcomes were an overall success. The reaction of the students on the project can best be summed up with a quote from one of the team members.

On the educational front, the structure and motion sub-team members fulfilled the academic objectives set forth by YCP for the design course and achieved their individual personal learning goals. Moreover, in addition to satisfying all required technical specifications, the sub-team's completed design earned recognition for creativity and innovation from IGVC judges and fellow competitors. 
Bibliography

[1] York College Engineering. York College of Pennsylvania, 2008. Web. 15 July 2011 $<$ http://depts.ycp.edu/mecheng/index.html>.

[2] ABET Inc., "Criteria for Accrediting Engineering Programs".

[3] Roboteq, "AX3500 Dual Channel High Power Digital Motor Controller User's Manual,," 2007.

[4] Intelligent Ground Vehicle Competition (IGVC), "The 19TH Annual Intelligent Ground Vehicle Competition (IGVC), Official Competition Details - Rules and Format," 2010 .

[5] U.S. Army, "Abrams - U.S. Army Fact Files," 24 July 2011.

[6] MATLAB Inc., "SIMULINK - Simulation and Model-Based Design".

[7] Dassault Systèmes SolidWorks Corp., "SolidWorks," 2010.

[8] Parametric Technology Corporation, "Mathcad - Solve and document your most complex engineering calculations," 2010. 